\title{
"ROAD SAFETY SEQUENCE" - A NEW CONCEPT OF THE ROAD SAFETY MANAGEMENT IN POLAND
}

\author{
Andrzej Szymanek
}

Faculty of Transport and Electrical Engineering, Kazimierz Pulaski University of Technology and Humanities in Radom, Radom, Poland

*E-mail of corresponding author: a.szymanek@uthrad.pl

\section{Resume}

The article shows a fragment of the results of the author's concept of road safety management in Poland. The article shows the "program sequence" of the construction action of road safety management system in Poland. The main component of this "sequence" of actions to improve the road safety - should be the "road risk management model". It should be widely used in Poland as an element of knowledge and practices of international road safety management. It is primarily about the model of the Office for Land Transport Safety Authority in New Zealand adopted by the EU in its road safety policy. The article also presents other components of the author's concept, including the "3 levels" model of risk management, the idea of which is to isolate three categories of the risk associated with any transport system.

Available online: https://doi.org/10.26552/com.C.2021.1.F1-F10

\section{Article info}

Received 23 February 2020

Accepted 30 March 2020

Online 21 October 2020

\section{Keywords:}

road safety sequence (RSS), road risk management (RRM), LTSA model

ISSN 1335-4205 (print version)

ISSN 2585-7878 (online version)

\section{Introduction}

The average annual probability of a fatal traffic accident (approximately $2 \cdot 10^{-4}$ ) is 10 to 100 times higher than in other modes of transport. It is also higher in relation to occupational accidents in many industries. The annual costs of traffic accidents at the rate of 1-2\% of GDP (depending on the level of development of the country) are a big economic problem. In the road transport is the largest potential of risk reduction of fatal and serious accidents. These are just some of the important reasons to become a subject of interest to road safety (RS). However - what is paradoxical - until the end of 2012, there was no standard for the road safety management - it has become only the ISO 39001 [1].

For years, there is a call for construction of a solid theoretical basis for road safety research. For example, the OECD document indicated the need for construction of theories and models for the road safety [2]: "no theoretical basis is unfortunately more common in road safety research than in many other areas of research". Since then, there has been considerable progress in study of the road safety, but still there is a need to develop a theoretical basis and a consistent methodology in this regard. These are the foundations for construction of national and international road safety management systems.
The risk of road accidents is the primary way of measuring the road safety, while "risk management of the road accidents", is the primary means of influencing the level of road safety. This interpretation arises from the "safety operationalization", that is, the ability to measure and control the risk. In turn, the acceptance of the thesis of the "acceptable level" of risk is the cornerstone of the methodology for the risk managed and tip for regulators in the various modes of transport. Thus, the risk management is a central concern of each project to improve the road safety. The research paradigm is also the basis of the concept of the road safety management in Poland, presented in this article.

\section{The main reasons and thesis for development of the concept of the road safety management in Poland}

Analysis of the state of research in the field of the road risk management (RRM) allows for the formulation of the rationale for development of the concept of the road safety management (RSM) in Poland [3]; here are some of them.

(1) In development of a research methodology for the road safety can be seen both evolution and jumps. Formulated new objectives and new research criteria 
RS would consolidate in the form of "good practices" and then other unsuitable would disappear. In projects relating to RS an important role carried out terms such as: prioritising objectives, determine scopes of competence and responsibility, improve the allocation of resources, the mechanisms for financing transport investments, institutional management [4]. The strategic approach to eliminating of fatal and serious road accidents and formulation of the principle of shared responsibility for the status of the RS turned out to be important. Large national programs: The Dutch Sustainable Safety and Swedish Vision Zero were created [5-6].

(2) Until recently, there were no risk management standards in the road transport commonly recognized as the „best”. Only the ISO 39001 Road Traffic Safety Management standard, published at the end of 2012, was dedicated strictly to the road safety management.

(3) In connection with the fourth EU Road Safety Programme and the United Nations Decade project; neither Action for Road Safety 2011-2020 created better opportunities to work on new management concepts RS in Poland.

(4) Projects to improve the RS should take into account the so-called „Gerondeau paradox” [7]: „Anyone road user is responsible for his behavior, but only the authorities are responsible for the overall level of road accidents"

(5) Projects to improve the RS should take into account the Adams' idea that the balance in risk management is the basis of its effective management. Disregarding this thesis can cause two opposite errors: 1 . error of ignoring the costs of risk reduction; 2. error of ignoring environmental and social risk factors [8].

(6) New projects of the road risk management should take into account:

- The ability to control the primary and secondary risk factors.

- The role of the transport infrastructure for emergence of threats.

- The role of traffic processes and control processes on formation of risks.

- Scale of the impact on the population groups (social risk context).

- Scale of the impact on the environment (environmental risk context).

The construction of each project to improve the road safety requires formulation of numerous working theses, to classify problems and directs research in the field of construction models and the road risk management methodology. Theses such as shown in [3]; here are the most important of them:

(1) The nature of safety in different systems is often identical, sometimes similar, it is advisable to use a legitimate analogy and the theoretical results of constituting science of safety. This is the thesis of W. J. Geysen and it can be adapted to needs of the road safety management concept in Poland [9]: safety in road transport can be shaped through the risk management and road events and management of losses on the road traffic, using the methodologies known from other systems risk management techniques.

(2) Accidents are effects of the existence gaps in the system of management, and therefore safety prevention must rely on locating, defining and removing these gaps. This thesis is based on the theory of J. Reason that - especially in the Swiss Cheese Model, (SChM) postulated the need for a study of two kinds of gaps, that is latent conditions and active failures, as the main causes of accidents [10]. The idea that one can use to develop a defense-in- depth strategy in the road safety management.

(3) The road transport is a complex system, in structure and working processes of which one can find different „varieties of safety", such as: a) Safety of traffic processes; b) Safety load processes; c) Functional safety (safety control devices); d) Safety (and reliability) of the human factor; e) Occupational safety in the road transport sector; f) Safety of critical infrastructure (bridges, tunnels, etc.); g) Safety of means of road transport; h) Environment safety.

(4) Road transport is a complex system, in the structure and working processesof which one can find that the principles and general methodology of the road transport risk management are the same as for other technical areas of human activity. Therefore, the risk management process steps are the same road as the general steps of the risk management process. What is specific for the road transport is included in all of this „superstructure” risk management processes.

(5) Traffic road safety can be interpreted as "product”, whose final form are observable results of safety outcomes, in particular road accidents. This is the thesis related to the LTSA (Land Transport Safety Authority) model, which is currently an international model for the construction of the national road risk management models.

(6) All the kinds of risks that are associated with the road transport can be classified in three levels of the road safety system - this is a thesis related to the author's concept of the "three levels" of the risk management in the road transport system, [11]:

- Structural risks - derived from interaction of structure system elements.

- Functional risks - derived from operation of the system.

- Behavioral risks - derived from effects (negative) of behaviors of the system.

\section{Road safety system concept in Poland}

The concept of the road safety management in Poland was described in the monograph Szymanek [3] and in this article shows its improved version, but limited to the main items. 


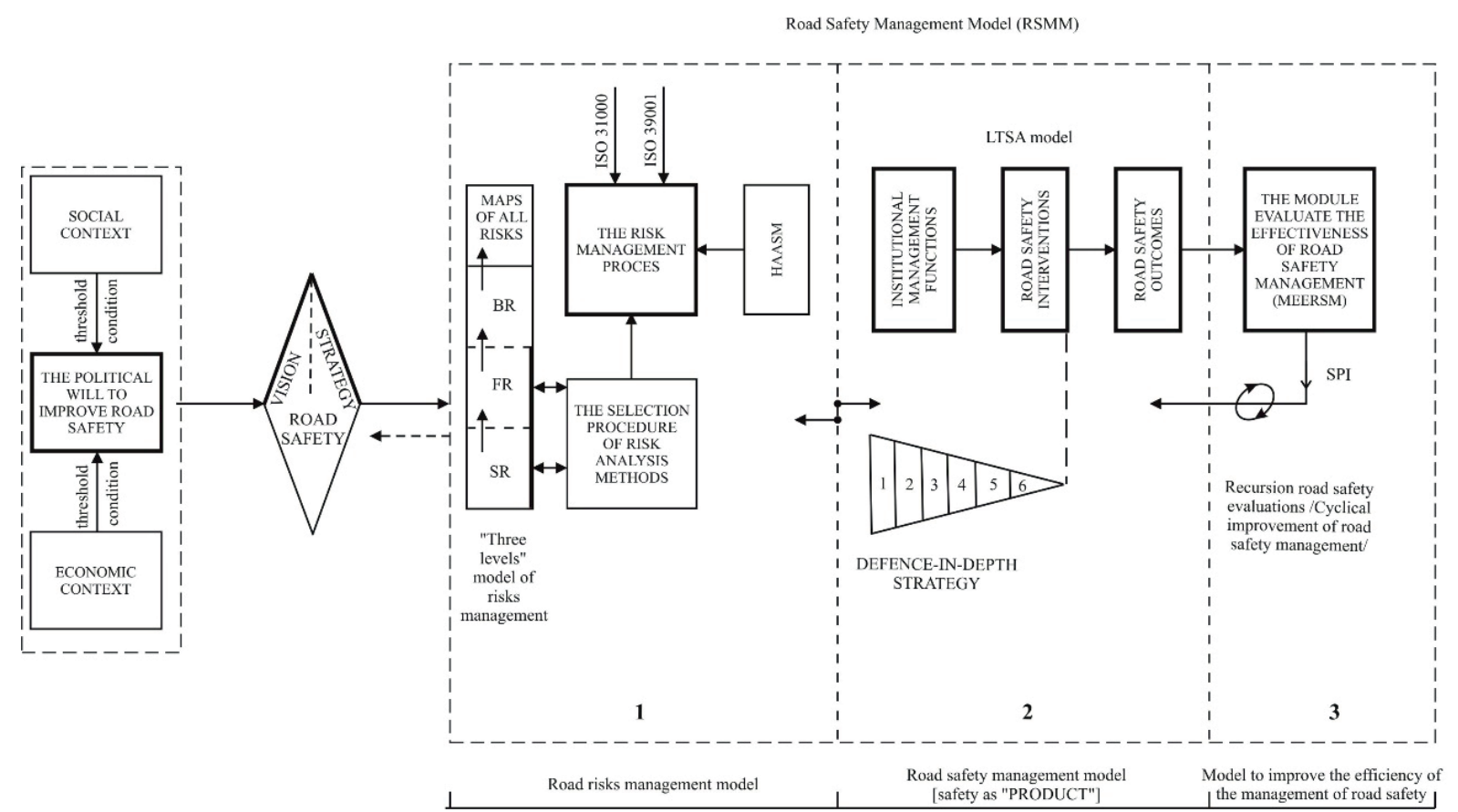

Figure 1 The concept of road safety management system in Poland

Program sequence of building the road safety management system in Poland (RS SEQUENCE) begins a strategy to improve the road safety (RS STRATEGY), which should be developed within the current Polish transport policy. Formulating a vision and road safety policy is always a conditio sine qua non for the construction of a road safety program and basically every process and system of road safety management starts from that. A factor that initiates creation of a vision, then the road safety strategy is the political will to improve road safety in the country (political will RS). It appears when the "threshold conditions”, associated with the socio-economic environment (context), are exceeded. As an example of the "threshold condition”, a popular interpretation of the " Smeed's right” can be quoted: „the number of deaths in any country is the number the country is willing to tolerate" [12].

This interpretation has been confirmed a few times: each country has achieved its "Smeed's point" at some moment of development. So it was in Poland after a critical 1991 year - the „critical mass” of road accidents was reached. And a few years later, GAMBIT was developed, the first national program to improve the road safety in Poland.

The road safety strategy enforces construction of the road safety management system (RSMS). According to the concept RSMS, presented here, the model can be described by:

- $\quad$ Road risks management model (RRMM);

- $\quad$ Road safety management model (RSMM);

- Module evaluate the effectiveness of road safety management (MEERSM).

A diagram of the proposed safety management system is shown in Figure 1. Into the RSMS should enter The following elements of knowledge and practice of international road risk management, previously widely used in Poland, should enter the RSMS:

- $\quad$ LTSA model of the road safety management [13]; this model is adopted by the European Union in its road safety policy.

- $\quad$ Road safety management model (RSMM).

- "Three levels" model of risk management (3RM), whose idea is to develop "maps of all risks" associated with the road transport (further: with any transport system); there are three levels of risk of system characterization: structure, work processes and "behavior" of system [3, 13].

- Defense-in-depth strategy. A Polish methodology of building-in the road safety management system of various protections in all the critical points of the transport system and at all the levels of the management of such a system should be developed.

- $\quad$ Standard AS/NZS ISO 31000: here that means use of the overall RMP [14].

- Standard ISO 39001 - dedicated exclusively to the management of safety in the road transport, at the same time a little yet known [1].

In the draft , efforts to improve road safety” the final product are the results of the safety outcomes. These include, first of all, the road traffic accidents, especially fatal and serious accidents. These results must be evaluated independently and reliably. This is to be the module to evaluate effectiveness of the road safety management, (MEERSM). Measures of effectiveness of this would be, of course, Safety Performance Indicators (SPI), whose methodology was developed in the framework of the project SafetyNet. Based on, inter alia, the SPI module this should force a RSMS modification. This means the correction in the management of the road/transport risks, 


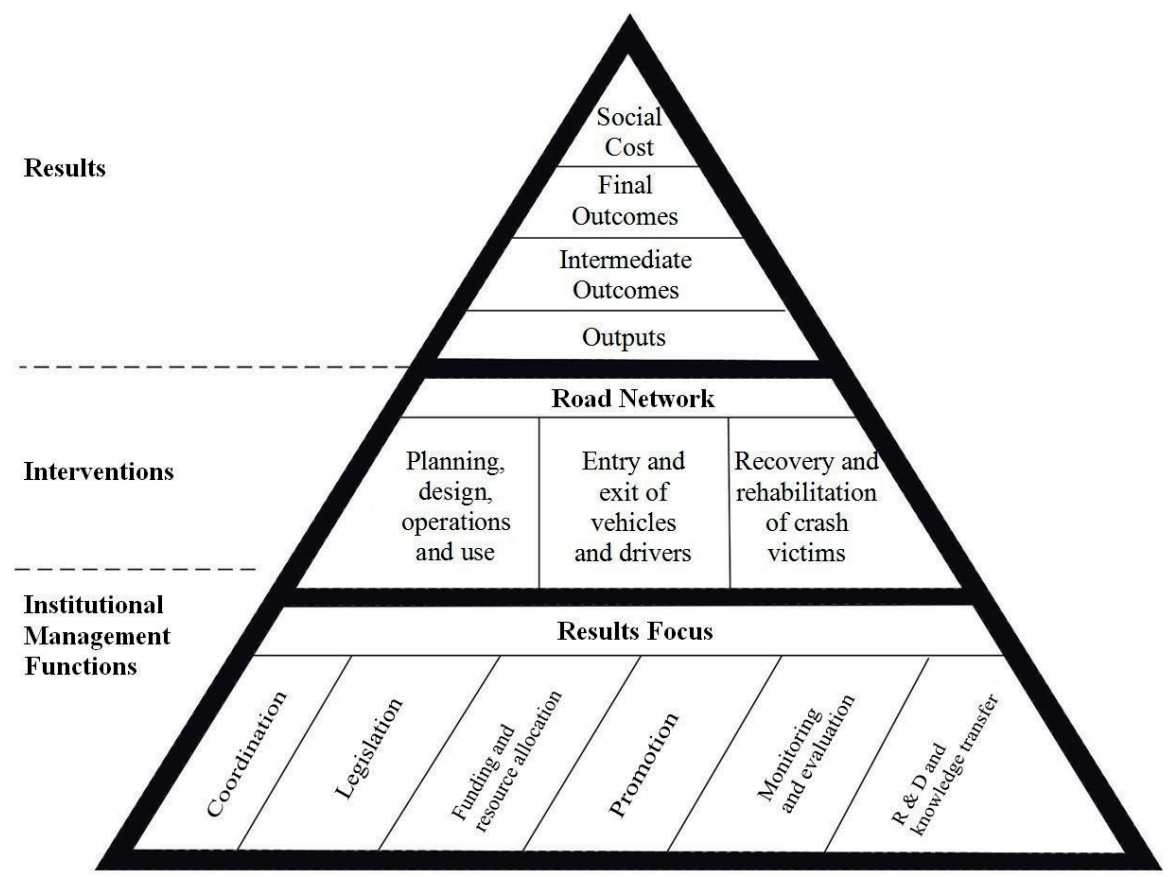

Figure 2 LTSA model of the traffic safety management [13]

thus that means modifications of the RSMS, which must of be a recursion type (Figure 1).

It comes to cyclical improvement of the RSMS, that is, efficiency improvement of the road safety. Information about the SPI values, arising from MEERSM module, should cause positive feedbacks, continuously improving the working RSMS system, Figure 1.

\section{LTSA model as the basis for the construction of a system for the road safety management in Poland}

The road safety management model in Poland must be built on the modern methodology foundation - conformity with the guidelines of the EU transport policy. These conditions meet the New Zealand Land Transport Safety Authority, which has been adapted by the European Safety Transport Council and is recommended by the World Bank.

It should be noted that the concept of the road safety management described in the LTSA model found its reflection in the standard ISO 39001. It has a double and important meanings:

- Meanings that the LTSA philosophy of the road safety management has been recognized by ISO experts in the right direction for the construction of the road safety management systems.

- Meanings that the Polish model of the road safety management, described here, is a part of the latest international trends in this area.

According to the LTSA, the road safety management should be seen as a 3-level process, in which the "product" is the „road safety”. This „processing of road safety” has to rely on the continued improvement of the intermediate and the final results of the road safety. The idea is a continuous improvement of the fatalities and serious road accidents reduction process. This philosophy should also set the goal for a future Polish road safety management system.

In the LTSA model there are three levels of the road safety management, Figure 2:

- Management by institutional management functions (IMF), which have run specific interventions to improve road safety.

- Managing through the road safety interventions (RSI) - that is actions improving results of the road safety.

Managing through evaluation of intermediate and final outcomes.

What is needed is a Polish version of the LTSA model. A preliminary description of the Polish version of the IMF is shown in [3]. For example, in terms of the IMF1 it is proposed to include:

- The term national and regional objectives of improving the road safety by the year 2020 and beyond based, inter alia, on the results of the research programs GAMBIT (2005) and ZEUS (2009-2010); see [15].

- Development of Polish versions of road safety indicators by the National Road Safety Council.

- To determine the value of the maximum individual/ personal risk of death in traffic at $5.2 \cdot 10^{-5}$ [1/year], by 2020 , which means about 2000 deaths, that is a reduction of about $50 \%$ in comparison to the year 2011 .

- To determine the acceptable social risk of death in traffic in accordance with the criteria of the EU.

The specification of the „Polish” institutional management functions, proposed in works by Szymanek [3, 16], will be helpful to the inventory of "holes” in the RSMS.

Adaptive treatments also require the „road safety interventions" as the second-level components of the management model of the LTSA. Such interventions are the result of implementation of the IMF and will depend on 
the circumstances of the Polish RSMS system. That is why their specification should be the subject of wider discussion among people dealing with the road safety research in Poland. Reference material is contained in results of GAMBIT (2005) [17].

The third management level "road safety effects" - these include results of the intermediate and final road safety. The final road safety outcomes show final performance built and implemented road safety management system (RSMS). The LTSA management Safety Performance Indicators apply to the effectiveness rate, SPI, in the third stage. In the next Polish RSMS the SPI indicators developed in the EU project SafetyNet and saved in the "Handbook of SPI", should be used [18-19].

In SafetyNet project, the SPI methodology is developed for the seven key problem areas of the road safety: 1) alcohol, medicines, drugs; 2) speed; 3) protective systems (passive); 4) the use of headlights during the day; 5) vehicles; 6) roads; 7) management of trauma.

Areas 1 and 2 relate to behavior of the road users and are the direct causes of traffic accidents. Areas 3 and 4 relate to prevention of accidents and their consequences, which relate to the reduction of the risk of accidents. Areas 5 and 6 are related to design and technical safety interventions. Area 7 relates to the road accident care and rescue systems.

In the report of the 2005 SafetyNet, the construction schemes and calculations of these seven key indicators of the SPI are provided [20].

It is also proposed to adopt the main EU macro-factors of exposure, risk and consequences of the road accidents. They are a tool for reliable and readable information on the impact of the various measures and remedial action on the level of road safety. The basis for discussions about the future of the Polish macro-indicators of the road safety should be a wide list of indicators of this kind adopted in EU road transport security policy [3, 21].

\section{General model of the road risk management in Poland}

The road risk management has specific characteristics, but does not differ essentially from the risk management of other systems. This issue concerns the working thesis No. 4 posted earlier. It follows that the risk management process model in Poland should be supported on two pillars:

1. The overall risk management process formula technique - adaptation of the latest formulas, "the overall risk management process" from the standard [1, 14].

2. "Superstructure" risk management process, which is the specificity of the road safety in Poland. The superstructure components that form the LTSA, thus the IMF, interventions and the results of road safety. In addition, the "superstructure" components will be measurable components of the risk management process, as the risk indicators, indicators of risk exposure and the macro-parameters of the road safety.
These ingredients of the Polish road safety management system will be distinguished from other such systems. Conclusion: the risk management processes in different technological systems have similar "general topology of process", but at the same time have a "variety of the process superstructures".

An essential ingredient of the road safety management concept, presented here, is the general scheme of the risk management process. It is the result of an analysis of several risk management standards and it has many borrowings from the standard AS/NZS ISO 31000. The risk management scheme is concurrent with the concept of the Enterprise Risk Management.

\subsection{The concept of "three levels" of the road risks management}

In transport, there are different risks; some of them generate a starting ,accident sequence”, which may or may not end in a transport accident. These risks appear in three „places” of the road transport system:

- The structure of the transport system,

- Work processes of transport system and

- Behaviour of the transport system.

It is the main idea of the "three levels" model [11]. It shows three interpretations of any general system:

1. Interpretation of the definition of "structure" (internal construction system).

2. Interpretation of the definition of "function" system, which are identified by the work processes changing ownership.

3. Interpretation that defines the "behaviour" of the system.

The structural interpretation of the system refers to definition of L. von Bertalanffy, according to which the system is a "collection of items remaining in their relations" [22]. Definitions of this type describe the system by means of: a collection of components; a collection of relationships between elements and objective - as a system relationship.

Interpretation system is derived from the functional definition by M. Mesarovic: "the system is a set of relationships between its characteristics" [23]. By studying these relationships one can determine whether the system is abnormal or not. Each system has certain characteristics and changing one or more characteristics is the event. A string of such events determines the functioning of the system and its effects (here: road accidents).

Here is a working thesis of the „three levels” model of the risk management: risk management takes place on three levels of road safety management system:

1. At the level of structure by managing interactions of structure elements,

2. At the level of processes, through the management of work processes in the road traffic and

3. At the level of "behaviours" through risk management, to minimize the negative effects of transport (NET). 
Table 1 Possible structural risks in the road transport. Fragment of theoretical classification

\begin{tabular}{lll}
\hline risk type & interaction of risk factors & structural risk factor \\
\hline & 1-argument mathemat. relations & \\
$\mathrm{R} 1$ & $\mathrm{HF} \rightarrow \mathrm{A}$ & faults and dangerous behaviors of traffic participants \\
$\mathrm{R} 2$ & $\mathrm{MRT} \rightarrow \mathrm{A}$ & damage means of road transport \\
$\mathrm{R} 3$ & $\mathrm{TI} \rightarrow \mathrm{A}$ & defect/damage of transport infrastructure \\
$\mathrm{R} 4$ & $\mathrm{CRE} \rightarrow \mathrm{A}$ & influence of natural environment factors \\
$\mathrm{R} 5$ & $\mathrm{~N} \rightarrow \mathrm{A}$ & wrong norms, bad rules \\
& 2 -argument mathemat. relations & \\
$\mathrm{R} 6$ & $\mathrm{HF} \wedge \mathrm{MRT} \rightarrow \mathrm{A}$ & wrong fit of means of transport to human-operator \\
$\mathrm{R} 7$ & $\mathrm{HF} \wedge \mathrm{TI} \rightarrow \mathrm{A}$ & wrong reading of transport infrastructure elements \\
$\mathrm{R} 8$ & $\mathrm{HF} \wedge \mathrm{CRE} \rightarrow \mathrm{A}$ & influence of natural environment on human operator \\
$\mathrm{R} 9$ & $\mathrm{HF} \wedge \mathrm{N} \rightarrow \mathrm{A}$ & wrong norms, bad rules \\
$\mathrm{R} 10$ & $\mathrm{MRT} \wedge \mathrm{TI} \rightarrow \mathrm{A}$ & effects at: means of transport - transport infrastructure, e.g. aquaplaning effect \\
$\mathrm{R} 11$ & $\mathrm{MRT} \wedge \mathrm{CRE} \rightarrow \mathrm{A}$ & influence of natural environment on mean of transport \\
$\mathrm{R} 12$ & $\mathrm{MRT} \wedge \mathrm{N} \rightarrow \mathrm{A}$ & norms of reliability and safe for means of transport \\
$\mathrm{R} 13$ & $\mathrm{TI} \wedge \mathrm{CRE} \rightarrow \mathrm{A}$ & influence of natural environment on transport infrastructure \\
$\mathrm{R} 14$ & $\mathrm{TI} \wedge \mathrm{N} \rightarrow \mathrm{A}$ & norms of designing and IT exploitation \\
$\mathrm{R} 15$ & $\mathrm{CRE} \wedge \mathrm{N} \rightarrow \mathrm{A}$ & rules of environmental conditions of transport safety \\
\hline
\end{tabular}

From the above arguments three levels transport risks are due:

- $\quad$ The $1^{\text {st }}$ level - "structural risk" (SR); therefore a need arises of a logical classification of risks. Helpful is here the classification proposed in [11].

- The $2^{\text {nd }}$ level - "functional risks" (FR) - generated by unwanted changes in traffic, traffic control processes and load processes.

- The $3^{\text {rd }}$ level - "behavioral risks" (BR) - those are the risks of emergence of the "negative effects of transport" (NET), i.e. transport accidents, traffic congestion, environmental degradation.

Structural risks - SR. At a structural approach to interpretation of the road transport system (basically any system) can be considered risks at the level of "the structure of the system". They are conventionally called the „structural risks” and defined as follows: structural risks come from the risks which are the effects of such changes in the interactions between the elements of the system, that can generate losses in the system and environment. Sources of structural risks are undesirable operating transport infrastructures and means of transport, as well as dangerous errors and infringements, in those places of the system where there is a cooperation with a man (human factor is also an element of the structure of the transport system).

Need arises for classification of risks. A method that relies on a review of the logical implications is proposed in [11]: risk factor (RF) accident (A).

Consider the five main groups of risk factors present in the road transport system: HF - the human factor; MRT means of road transport; TI - transport infrastructure; CRE - close road environment; $\mathbf{N}$ - standard, norms.

Each of these risk factors may occur either alone or jointly with others, which conventionally can be saved by the logical conjunction operator (traditionally denoted by a symbol $\wedge$ ). Then the total number of structural interactions NSI in the system is the sum of combinations without repetition - rows 1 to 5, namely:

$$
N S I=\sum_{i=1}^{5} \frac{1}{i !} \cdot \frac{5 !}{(5-i) !}=31 \text {. }
$$

Equation (1) above gives a theoretical number of structural types of risks in the system, in which it identified the five main groups of risk factors. To the structural risk factors here concerned one needs to add five others that are defined by implications of the same arguments. The general classification of 33 structural categories of the risk factors is presented in $[3,11]$; here is shown a small portion of it, Table 1.

The author cannot name aggregate risks R16-R33. One can only say that these risks are the result of a greater number of aggregated risk factors. So, these risks are more and more "systemic".

Functional risks FR. Structural risks can transform into danger of the "2 $2^{\text {nd }}$ level”. It's about the risks of such changes of ownership of a road system that the system and environment can be losses generated. Risks associated with changes in these properties is "functional risk" - that is, the risk of undesirable changes important for safety of the working processes in the system.

Therefore, the interpretation „of the process approach to transport system" is used. According to it transport activity consists of three basic processes:

1. Process of shaping the transport infrastructure: a. planning of infrastructure; b. implementation of infrastructure; c. the operation of the infrastructure.

2. The process of providing a transport service aimed at the flow of people, goods and information. This process 
includes organizational, regulatory and administrative elements.

3. Process of creation of the transport policy - is a process of management that ensures the integration and coordination of all elements of the transport system.

Functional risks in transport system may be classified as follows:

- $\quad$ FR1 - the risk of faulty infrastructure formation:

- $\quad F R 1_{1}$ : the risk of faulty planning of infrastructure - depend on: an incorrect location; erroneous predictions; disadvantages of financing plans;

- $\quad \mathrm{FR} 1_{2}$ : the risk of poor implementation of infrastructure - dependent on such risks as: wrong selection of contractors; defective construction work; errors in works monitoring;

- $\quad \mathrm{FR}_{3}$ : the risk of incorrect operation of the transport infrastructure - dependent on: faulty repairs and modernization; erroneous analysis of investment effects.

- $\quad$ FR2 - the risk of faulty transport services - dependent on:

- $\quad \mathrm{FR}_{1}$ - the risk of faulty organization of the transport process;

- $\quad \mathrm{FR} 2_{2}$ - executive risk in the transport process;

- $\mathrm{FR}_{3}$ - administrative risk in the transport process;

- $\mathrm{FR}_{4}$ - risk cargo in transport process;

- $\mathrm{FR}_{5}$ - the risk of traffic (road, rail, sea, air).

- $\quad$ FR3 - the risk of erroneous transport policy - depends on:

- $\mathrm{FR} 3_{1}$ - the risk of erroneous macro-forecasts of transport development;

- $\quad \mathrm{FR}_{2}$ - faulty risk management (the impact of state public-law bodies on transport users).

Behavioral risks BR. Functional threats initiate unwanted behavior of transport and these, in turn, can result in appearance of the negative effects of transport (NET); these are primarily accidents and collisions, but one can also consider other road traffic systems. The NET-s are on the 3rd floor of the related behavioral risks. They can be applied in road safety policy of the EU, through the SPI.

\subsection{Defense-depth strategy in the road safety management}

Management of safety in transport is a management of „loss avoidance” that can occur at any level and in any place of the specific transport system. Such a management requires methodology of multiple levels of security, in all of the identified critical points of the transport system and at all the levels of the management of such a system. It is a methodology consistent with the strategy of deep defense [24].

To the concept of „defense-in-depth” connect Reason's Swiss cheese model - accidents are effects of gaps in the management of the system [25]. In this model, the crucial importance have layers of protection („cheese slices”) with differently situated „holes”, which is the two-fold gaps:
1) active faults (failures); 2) latent conditions. Reason postulated the need to study such loopholes as major causes of accidents. This model was used, inter alia, in investigation of traffic accidents [26].

In this model is the interpretation is the following: an accident may occur as a result of imposition of dangerous behavior and actions of the driver, road management problems, the vicious traffic and surveillance and the so-called latent conditions, that is "holes” in the Swiss cheese. If at some point of time and the point of the road network "holes” (sometimes called the „windows way”) would be simultaneous - it would cause a traffic accident.

Within the deep defense safety strategy there are integral safety barriers, which play a big role in understanding and prevention of accidents. The standard IEC 61511-1 defines a protective layer: "any independent mechanism that reduces the risk by the control, prevention, and weakness" [26]. The main message of the barrier analysis is the password: "hold the threat away from the target."

The deep defense strategy can be interpreted by the blunt-sharp-end model. It specifies the next phases to prevent activation of remote threats (closer to the „blunt end”) and stopping local threats („here and now”) on the „sharp end". This can be implemented in the next layers of defense that correspond to the levels of safety management. Impact on the risk of an accident is remote in time („blunt end") and the nearby at the time („sharp end”). The strategy of „deep defense” is avoiding errors and use of defense - as soon as possible, from the blunt end.

In the road transport, one can specify the following levels of the road safety management [3]:

1. Creation of a high safety culture - reducing the social consent for high risk of the road accidents,

2. Safety policy planning - development and implementation of vision and improving programs of the safety transport,

3. Management of the road safety at the level of regional and local authorities and road administrations,

4. Safety management work of transport operators,

5. Risk management of road accidents and

6. Reducing the effects of road accidents.

\subsection{The concept of the analysis methods selection for the functional and structural risks}

The risk analysis methods describe identification of probabilities and consequences/losses associated with the adverse events in the considered system.

For analysis of risks in a particular road transport system crucial is reliable, that is complete and accurate identification of potential threats. Choosing the right method for the hazard identification and risk analysis is a critical moment in the procedure for risk assessment. Success depends on relevancy of this selection. There is no one criterion for selection of methods. Which of the methods one would choose depends on the purpose 
Table 2 The concept of the risk analysis methods selection for the structural and functional risks in the road transport

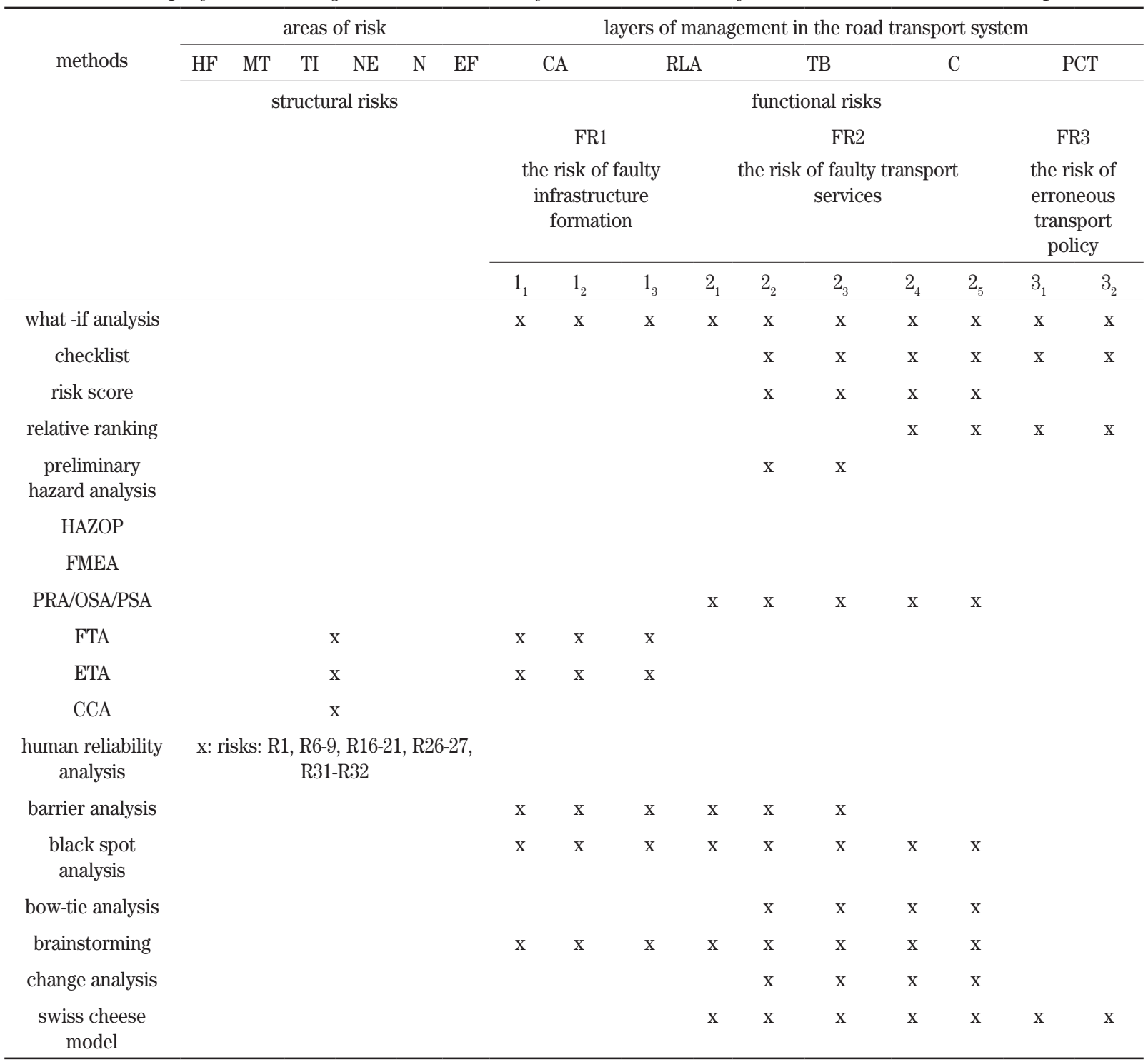

$\mathrm{x}$ - is a possible method to apply

and scope of the risk analysis, as well as the preferences of a team undertaking an analysis, its experience and availability of similar analysis objects (sometimes called as referred objects).

There is no "the best” method assigned to specific applications. It is therefore entitled to declare: the selection of an appropriate method of risk analysis is more art than science.

Guided by the above criteria, very preliminary proposals for selection of the analysis methods for the functional and structural risks for road transport were developed. Table 2 was published in the papers [11, 25].

Selection of methods of risk analysis in the road transport system depends on the conventional "areas of risk" and "layers of management in the road transport system". Those areas are identified by the five main groups of risk factors present in the road transport system, described in this article: HF - the human factor; MT - means of transport; TI - the transport infrastructure; NE - natural environment; $\mathrm{N}$ - standard, norms. In addition, the area: $\mathrm{EF}$
- external factors (floods, terrorist acts) was considered, as well.

Layers of the transport system: CA - central authorities; RLA - regional and local authorities; TB - transport boards; C - carriers; PCT - producing companies for transport.

\section{Conclusions}

The main interest in this work was to answer the question: what should be the program "sequence of actions to improve the status of road safety" in Poland? Attempt to answer to question is contained in the work [3]. In this text, a "sequence" in summary form version is shown, but as newer and essentially enriched.

Any project for the road safety improvement is located in the wider project - a project to improve quality of the road transport. In order to realize that, it is necessary to ensure: 1. Minimum nuisance for the natural environment. 2. The maximum level of safety. 
Realization of the above objectives means the need of implementation of the $5 \mathrm{E}$ methodology (EducationEngineering-Enforcement-Encouragement-Evaluation).

Construction of projects to improve the road safety (widely: the road transport safety) in Poland must be supported by scientific research. That research is defficient or even unknown in Poland. Here is a brief list of suggestions in this regard:

1. Development of a Polish methodology of identification of gaps in the traffic management system. It is about latent failure conditions in the management and active management errors; based on the Reason's theory;

2. Continue work on selection criteria and methods of risk analysis, the most useful for transport systems and traffic;

3. Interpretation and adaptation to the conditions of Institutional Management Features IMF known from the LTSA model road safety management;

4. Development of model "3-levels of road risks management"; the excerpt is shown in this article;

5. Adaptation of the "deep defence strategy" for the road safety management.

\section{References}

[1] ISO 39001. Road traffic safety (RTS) management systems - requirements with guidance for use. 2012.

[2] OECD. Integrated strategies for safety and environment Road Transport Research. Paris, 1997.

[3] SZYMANEK, A. Theory and methodology of traffic risk management / Teoria i metodologia zarzadzania ryzykiem w ruchu drogowym (in Polish). Radom: Wyd. Polit. Radomskiej, 2012. ISBN 978-83-7351-505-5.

[4] BLISS, T. Implementing the recommendations of the world report on road traffic injury prevention. Transport Note No. TN-1. Washington D.C.: The World Bank, 2004.

[5] TINGVALL, C. The zero vision. In: 1st International Conference Transportation, Traffic Safety and Health: The New Mobility: proceedings. Springer-Verlag, 1995. p. 35-57.

[6] WEGMAN, F., ELSENAAR, P. Sustainable solutions to improve road safety in the Netherlands. SWOV Report D-97-8. Leidschendam, 1997.

[7] ABOURAAD, S., ELSENAAR, P. Road safety management in ESCWA countries critical issues in implementation. In: ESCWA-WHO Regional Conference: proceedings [online] [accessed 2020-02-18]. 2006. Geneve, Switzerland: Global Road Safety Partnership. Available from: http://www.grsproadsafety.org

[8] ADAMS, J. Complexity and uncertainty in a risk averse society. Three framing devices for managing risk. In: For Omega Conference: proceedings [online] [accessed 2020-02-18]. 2007. Available from: http://john-adams.co.uk

[9] GEYSEN, W. J. The structure of safety science: definitions, goals and instruments. In: 1st World Congress on Safety Science: proceedings. Vol. 1. 1990. p. 44 - 80.

[10] REASON, J. Managing the risks of organizational accidents. Aldershot: Ashgate, 1997. ISBN 978-1840141054.

[11] SZYMANEK, A. Conception of 4 goals and 3 levels of risk management in road transport systems. Archives of Transport [online]. 2010, 22(3), p. 359-375. ISSN 0866-9546, eISSN 2300-8830. Available from: https://doi.org/10.2478/v10174-010$0022-1$

[12] SMEED, R. J. The usefulness of formulae in traffic engineering and road safety. Accident Analysis and Prevention [online]. 1972, 4(4), p. 303-12. ISSN 0001-4575. Available from: https://doi.org/10.1016/0001-4575(72)90029-2

[13] Land Transport Safety Authority. Road Safety to 2010. Wellington, New Zealand, 2003.

[14] ISO-DIS 31000. Risk management - principles and guidelines on implementation [online] [accessed 2020-02-20]. Draft International Standard ISO/DIS 31000. International Organization for Standardization, 2008. Available from: http://rmia. org.au

[15] KRYSTEK, R. Integrated transport safety system / Zintegrowany system transportu (in Polish). Vol. 1-3. WarszawaGdansk: WKL, 2009-2010.

[16] SZYMANEK, A. The concept of using SCh-M and LTSA models to identify management gaps in the Polish road safety system (Koncepcja wykorzystania modeli SCh-M I LTSA do identyfikaacji luk zarzadzania w polskim systemie bezpieczeństwa drogowego). In: 23rd International Scientific Conference TRANSPORT MEANS 2019: proceedings. Sustainability: Research and Solution. Part III, 2019, ISSN 2351-7034, p. 1170-1174.

[17] GAMBIT 2005. National Road Safety Program 2005-2007-2013 / Krajowy program bezpieczenstwa ruchu drogowego 2005-2007-2013 (in Polish). Warszawa: Ministry of Infrastructure / Ministerstwo Infrastruktury, 2005.

[18] HAKKERT, A. S., GITELMAN, V. Road safety performance indicators [online] [accessed 2020-02-20]. Manual. Deliverable D 3.8 of the EU FP6 project SafetyNet. 2007. Available from: http://erso.swov.nl/safetynet

[19] VIS, M. A., VAN GENT, A. L. Road Safety performance indicators: country comparisons. Deliverable D3.7a of the EU FP6 project SafetyNet. 2007.

[20] VIS, M. A., AMELINK, M. Safety performance indicators. In: 1st SafetyNet Conference: poster [online] [accessed 202002-21]. Deliverable No: D 3.5. 2006. Available from: http://ec.europa.eu/transport/ 
[21] Al-HAJI, G. Traffic safety in developing countries-new approaches in technology transfer by using distance education technique. Master's thesis. LITH-ITN-EX-2001:156-SE. Linkoping University, 2001.

[22] VON BERTALANFFY, L. General systems theory: foundations, development, applications. New York: George Braziller Inc., 1968. ISBN 978-0807604533.

[23] MESAROVIC, M. D., TAKAHARA, Y. General systems theory: mathematical foundations. 1. ed. Elsevier Science, 1975. ISBN 9780080956220.

[24] SZYMANEK, A. Defence-in-depth strategy in transport risk management. Communications in Computer and Information Science. 2010, 104, p. 51-58. ISSN 1865-0929.

[25] REASON, J. Human error [online]. Cambridge: Cambridge University Press, 1990. eISBN 9781139062367. Available from: https://doi.org/10.1017/CBO9781139062367

[26] SALMON, P., REGAN, M., JOHNSTON, I. Human error and road transport: phase two - a framework for an error tolerant road transport system [online] [accessed 2020-02-21]. Monash University Accident Research Centre Report Documentation Page. Report No. 257, 2006. ISBN 0732623278. Available from: www.monash.edu.au 